\title{
Representing the gods: the role of art and feeling
}

\author{
MARK WY N N \\ School of Philosophy, Australian Catholic University, PO Box 247, Everton Park, \\ QLD 4053, Australia
}

\begin{abstract}
This paper argues that we can fruitfully consider some central issues in philosophy of religion through the lens provided by the literature in aesthetics. Specifically, I argue that Mikel Dufrenne's theory of representation in the arts can be usefully applied to representations of the sacred. The paper seeks to trace some of the implications of this view for our understanding of religious language and the epistemology of religious belief. It also aims to throw light on the religious power of art, including art which lacks any explicitly religious content.
\end{abstract}

\section{Introduction}

In this paper, I shall draw on aesthetic theory to understand how 'the gods' may be represented. Specifically, I shall argue that Mikel Dufrenne's account of representation in the arts can be usefully applied to the language and imagery which are used to represent the gods. ${ }^{1}$ On Dufrenne's account, an artwork can render an object affectively present, and in that sense represent it, by evoking a set of feelings of the kind that recall the object. On first consideration, this approach may seem to offer a promising model of representation in religion, insofar as the gods are associated with a range of deeply felt responses. The paper argues that this initial impression can be sustained upon closer examination of Dufrenne's theory and various concepts of the sacred.

My application of Dufrenne's model to religion has two phases. First of all, I shall consider concepts of God or the gods which represent the gods as adequately disclosed in the world, in the sense of being imaged by or in some way bodied forth by various regions of human experience, or perhaps by our experience in its totality. Given some such concept of the divine, a representation of the world (or some region of human experience) will also serve as a representation of the divine. And accordingly, a work of art which represents the world (or some region of human experience) by evoking a set of feelings of the kind that recall the world will 
also thereby represent the divine. In the course of the paper, I shall offer a number of examples to bring out the sense of this proposal more precisely.

In the second phase of my application of Dufrenne, I relate his account to concepts of the sacred which think of God or the gods as only imperfectly revealed in human experience, or as entirely discontinuous with what is revealed in human experience. These concepts of the sacred also presuppose some understanding of how the feelings which are proper to the divine are to be related to the feelings which are proper to the world. (Of course, here the relationship is not one of replication.) I shall argue that this further sense of how the feelings appropriate to the mundane are to be mapped onto the feelings appropriate to the divine offers another way of seeing how the divine may be made present in experience, at the level of feeling, and in that sense represented.

Clearly, this general approach makes a number of assumptions about the nature of religion. It presupposes that participation in a religious tradition, and relating to the sacred in that tradition, requires (in the normal case) the adoption of appropriate patterns of affective response, both in relation to the world and in relation to the sacred. And it assumes that art is an important medium for inculcating such responses. The paper proposes that if art can play this role of shaping our affective sensibilities, and evoking various feelings of the kind that are fitting in relation to the world and the sacred, then (assuming the validity of Dufrenne's model) it can also play a part in representing the divine.

A number of similar themes are evident in John Wisdom's essay 'Gods'. For example, Wisdom also assumes that the divine is disclosed, not so much in relation to individual items of experience, as in terms of the patterns which are evident in whole regions of experience. ${ }^{2}$ In turn, identifying these patterns proves to be a matter of understanding the world as for example 'a garden'. Hence recognizing these patterns implies that a certain range of feelings is appropriate in relation to the world (it is 'tended' rather than 'abandoned'), and these feelings in turn inform the feelings we should entertain in relation to God ('the gardener'). In this discussion, Wisdom is also cognizant of the relationship between aesthetic and religious understanding. He notes, for example, that this sort of pattern recognition is presupposed in aesthetic appreciation, and he is in effect treating the world as a kind of artwork. The present discussion could be read as an extension of Wisdom's discussion, building on a number of his ideas: that God is revealed in relation to whole regions of experience; that religious and aesthetic understanding are in some way connected; and finally, that the feelings we entertain in relation to the world and in relation to God are in some degree mutually defining.

Before proceeding to the main body of the paper, I should try to clear away some initial difficulties. It might be thought that there is an air of paradox about the proposal that an artwork may represent the divine. After all, 'sophisticated' religious traditions think of the sacred as nonmaterial, and accordingly as free from any imaginative content. In fact, Dufrenne's account of representation is con- 
cerned with what we might call the 'nominal essence' of the represented object, and more particularly with the way it impinges upon us affectively. Hence in applying this model to representation in religion, I am not assuming that the divine can be literally pictured, for example. The account depends only on the thought that certain patterns of affective response are appropriate in relation to 'the gods'. Even an apophatic conception of God, which places God's real essence beyond the reach of human enquiry, is likely to be associated with such patterns of response, assuming that this conception plays some role in the life of a religious community.

Even so, there is a case for favouring some other expression in place of 'representation' in this account. However, I have kept the term 'representation' to make the connection with Dufrenne's discussion clearer, since this is the term he (or his translator) favours. But it is worth being clear that the notion of representation which arises here need not imply verbal description, or literally picturing, but only rendering present (or re-presenting) the object, insofar as it is recalled by way of various feelings. So the kind of representation which is relevant here could equally well be called affective disclosure.

Talk of affective responses to the divine, or rendering the divine affectively present, may suggest that I am presupposing that God, or the sacred understood in some other way, really 'exists'. So I should indicate that throughout I am intending to bracket this ontological question. The account I offer is meant to be internal to the various religious traditions discussed; in other words, I am taking for granted that the sacred as they conceive it is real, and asking how they succeed in representing the sacred, on this assumption. Of course, if we should suppose that a representation of the sacred is in some way mistaken, then we can ask whether it succeeds in referring to or representing anything at all. (Perhaps in that case it would succeed only in referring to a psychological complex?) However, I do not want to address that kind of issue here.

Central to Dufrenne's account of aesthetic experience is the thought that artworks may 'evoke' certain 'feelings'. The notions of 'feeling' and 'evocation' should also be clarified at the outset of this discussion. In speaking of artworks evoking various feelings, Dufrenne is using the term in a somewhat restricted, technical sense, so as to mark a distinction between 'feeling' and 'emotion'. Hence he writes that:

...the emotion of fear is not to be confused with the feeling of the horrible. It is, rather, a certain way of reacting in the face of the horrible when the horrible is taken as a characteristic of the world as it appears at the time, that is, as a means of struggling within the world of the horrible. ${ }^{3}$

Similarly, he distinguishes between the feelings of the comic and the tragic, and the emotions of merriment and terror or pity, considered as responses to those feelings. So on this view, feeling has a cognitive role. By means of feeling, we grasp the human significance of some entity or situation, identifying it as a tragedy (or, 
following Wisdom, as a garden), or as carrying some other meaning; it is then a further matter how we respond to that insight in emotional and other terms.

Setting aside this distinction between emotion and feeling for a moment, if we should say (in ordinary English) that an artwork evoked certain feelings (joy, despair, or whatever it may be), we could be taken to mean that it brought us to share in or undergo these feelings in a full-blooded way, or we might be taken to mean that these feelings were simply brought to mind, without being experienced in a full-blooded way. We might suppose that the second of these senses is the more appropriate in the ordinary case. It is natural to think that a tragic drama, for example, will not bring us to share, in a full-blooded way, the feelings we would expect to arise in relation to real-life tragedy; and accordingly, we may say that such a drama will 'evoke' the feelings we associate with real-life tragedy in the sense of calling them to mind, rather than in the sense of full-bloodedly reproducing them. (We may include in this category of calling to mind the case where the feelings are recalled because we experience less forceful copies of them.) If we are going to use the notion of 'feeling' in Dufrenne's technical sense, as I shall in this paper, then we need to make this point in a rather different way. In that case, we may say that a tragic drama may evoke, in the sense of bringing us to share, the same feelings as the real-life situation, but in general will not evoke, in the sense of bringing us to share, the emotional response we would expect in such a situation. Rather, in the normal case, it will simply recall that response.

\section{Mikel Dufrenne's theory of aesthetic experience}

I have chosen to make Mikel Dufrenne's theory the particular focus of this discussion not only for its own merits, but also because his work is in many ways representative of a larger tradition of thought, deriving from Schopenhauer and others. If his ideas are reflected in this wider body of literature, then we may feel reasonably confident that his approach faithfully records certain features of the phenomenology of aesthetic experience. For the purposes of this paper, it is not necessary that this 'expressive' account should apply to all artworks; it will suffice if, plausibly, it applies to at least some. ${ }^{4}$ Perhaps the easiest way of introducing Dufrenne's thought is by turning directly to his treatment of a range of examples, taken from a variety of art forms. Experience of the sea will provide a recurring theme in this paper, so I shall begin there. Dufrenne observes that:

When a poet invokes the sea, we genuinely feel the sea's presence.... It is present... with a presence we must call affective and with a truth of its own which can be discovered only through art. Thus art truly represents only in... communicating through... the sensuous a certain feeling by means of which the represented object can appear as present. ${ }^{5}$

Here Dufrenne suggests that an artwork may represent some entity or field of experience in the empirical world, by evoking a range of feeling which in some 
way recalls that entity. For example, referring to Debussy's La Mer, Dufrenne writes that: 'Something like the essence of the sea is revealed to me, with respect to which every image is gross and vain. We are concerned with what I experience when I am before the sea, of what there is of the truly "marine" in it - with its affective essence... ${ }^{6}{ }^{6}$ So Dufrenne thinks that artistic representation works, at any rate in part, and at least in some cases, by evoking a set of feelings which reproduce or in some way recall the feelings evoked by the represented object. This is the first basic theme in Dufrenne's aesthetic theory which I want to isolate for the purposes of the present discussion.

Dufrenne's description of other examples of aesthetic experience suggests a further kind of relationship which an aesthetic object may bear to the empirical world. Turning from poetry and music to architecture, he writes that:

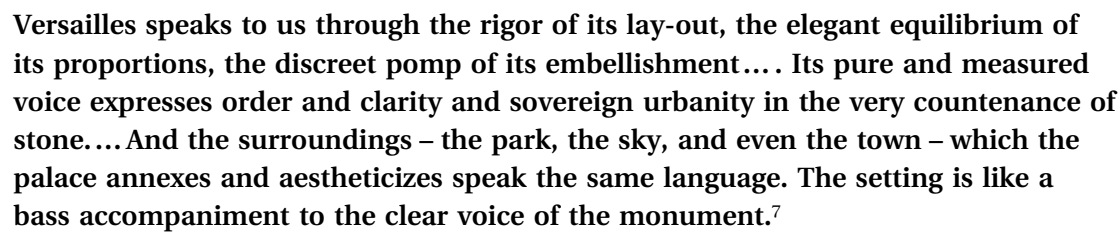

Here again Dufrenne speaks of an aesthetic object evoking various feelings. But in this case, the feelings do not serve to make a certain entity or scene present; rather, they constitute a kind of atmosphere which extends beyond the aesthetic object itself to embrace various things in its environment. The idea that a work of art can unite a number of things within a single order, whose character is defined in affective terms, leads Dufrenne to speak of artworks as 'expressing a world'. Parts of the empirical world may belong to such an expressed world insofar as they participate in the unitary affective tone which is projected by the artwork, just as the surroundings of Versailles are absorbed into its affective world in this example. Similarly, exploring this same theme, Dufrenne remarks that: 'The soft delicate tranquillity which is expressed by the interiors of Vermeer is not contained between the walls which the painting encloses. It radiates upon an infinity of absent objects and constitutes the visage of a world of which it is the potentiality. ${ }^{8}$

Although Dufrenne makes use of a somewhat specialized vocabulary to develop his account of aesthetic experience, the main elements of this account are, I suggest, recognizable to common sense. And this is how it should be, since Dufrenne's intention is to present a phenomenology of aesthetic experience. The thought that artworks engage us affectively, and may thereby represent an empirical object, in a language other than that of prose or science; and the idea that an artwork can transform our pre-existing affective relationship to items in the empirical world, by absorbing them into its affective world: these are widely held notions, although Dufrenne has the distinction of setting out these themes with unusual clarity, and a broad range of supporting examples. 


\section{Conceiving of the sacred}

Having set out some elements of Dufrenne's account of representation in the arts, we might examine next the nature of representations in religion. One familiar approach to this question has taken representations of the gods to reveal the character of whole regions of experience. For example, the stories of the gods of ancient Greece and Rome can be read as summary expressions of the quality of human experience in various fields - one god personifying love, another war, and so on. Now this might seem like a merely primitive way of thinking about the sacred. However, I shall argue, first, that it is a deep-seated tendency of the religious imagination, and for this reason merits serious consideration; and secondly, that this sort of understanding has found philosophically able exponents, and for this reason too bears further examination.

Anthropological studies of the beliefs of various primal peoples confirm the thought that this way of representing the gods, by reference to whole regions of human experience, is indeed a recurring feature of human beings' religious understanding. For instance, writing of a spiritual power in Inuit religion, Keith Ward comments:

Perhaps there may be those who take literally the story of the girl who began to eat her giant parents and was cast by them beneath the sea - the fundamentalists of Inuit religion.... [but] What is here represented in an image is the character of the sea itself, as a power for good and harm. What the shaman meets in the dreamquest is this internalised image of the powers which bound Inuit life. ${ }^{9}$

Similarly, Ward writes that this figure in Inuit religion, named Sedna, offers an 'eidetic representation of the harsh, often arbitrary-seeming and yet lifesupporting conditions of the arctic world ${ }^{\prime} .{ }^{10}$ Ward's account is easily supported by reference to other examples from the anthropological literature, where representations of religious powers are again seen to function as summary expressions of the quality of various regions of experience. ${ }^{11}$

Now this way of thinking is not confined, of course, to primal peoples or the religions of the ancient world. On the contrary, the Western tradition of philosophical theology exhibits the same propensity, insofar as it has drawn upon Platonic categories in order to understand the nature of God. To think of God as Goodness Itself, for example, is to suppose that God is revealed in relation to human experience in general, insofar as that experience discloses the nature of goodness. In other words, as in the case of Sedna, the focus here is not on individual items, but rather on whole tracts of experience; and as with Sedna, it is assumed that there is some sort of affinity between the nature of the world and the nature of religious powers.

Similarly, Aquinas conceives of God as subsistent existence, which is to say that God is revealed in relation to the totality of our experience, insofar as our 
experience provides an intimation of what it is to be. In keeping with this conception of God, Thomas is explicit that it is the world as a whole rather than individual things within it which offers our clearest image of the nature of God. ${ }^{12}$ This teaching, like the Platonic view, could be seen as an extension of the idea we have found in the primal traditions, according to which the divine is revealed in relation to the sea, or some other particular sphere of experience. Of course, Aquinas's representation of God as subsistent existence does not epitomize human experience in the way that Sedna or the Graeco-Roman gods epitomize human experience: Aquinas's account at this point is purely abstract. But supposing we want to know about God or the gods, Aquinas's account directs us to the whole field of human experience, and the Sedna complex similarly directs us to a whole region of human experience. In this respect, the approaches are in agreement.

Summarizing this general tendency of thought, the historian of religion, Mircea Eliade, comments that: 'The great paradox common to all religions is that God in showing Himself to mankind is free to take any form whatsoever but that, by this very assertion of His freedom, He "limits Himself" and reduces Himself to a mere fragment of the whole which He represents. ${ }^{13}$ Here again the divine is seen to bear some analogy to the whole field of human experience, rather than particular objects within it. And we might add that insofar as God is revealed in relation to a 'fragment of the whole', this is only because the fragment can function as a concrete universal, that is, as a compressed expression of the nature of the whole. It is easy enough to find modern theologians whose work exhibits this same tendency of thought. For instance, David Tracy remarks: 'To enter the conversation of the religious classics through real interpretation... is to enter a discourse of a world of meaning and truth offering no certainty but promising some realized experience of the whole by the power of the whole. ${ }^{14}$ And in a similar vein, in a recent encyclical, John Paul II has written that: 'In the Incarnation of the Son of God...the Eternal enters time, the Whole lies hidden in the part. ${ }^{15}$

\section{Applying Dufrenne's model: the Sedna case}

So far, we have considered Mikel Dufrenne's understanding of representation in the arts, and we have taken note of one recurring response to the question of how 'the gods' are to be represented. Next I want to examine some areas of overlap between these two approaches to representation. In exploring these areas of overlap, I shall begin with the case of figures like Sedna. For these purposes, when I speak of 'Sedna', unless otherwise indicated, I shall mean the character expressed in various images and stories, rather than the power of the sea which this character represents.

As we have seen, Ward suggests that Sedna functions as an eidetic representation of the sea, and that in representing the sea, she thereby represents the 
religious power at work in the sea. Now we might wonder how the figure of Sedna succeeds in summing up the character of Inuit experience in relation to the sea. I shall assemble a number of arguments in support of the claim that Sedna's powers of representation are basically aesthetic.

Plainly, Sedna does not sum up the nature of the sea in Inuit experience in the manner of a scientific formula, or in some other abstractly conceptual fashion. Rather, Sedna is able to epitomize the sea as it is revealed in Inuit experience by virtue of the various images and stories which record her deeds and personality. This use of images and stories suggests that the kind of representation which arises here is aesthetic. Moreover, quite apart from the manner in which her nature is recorded (by means of stories and images, rather than abstract concepts or scientific formulae), the existential point of a figure like Sedna should anyway lead us to think of her representational powers in these terms. For the Inuit interest in the sea is, of course, not of a scientific kind, or of an abstract, speculative kind, but grounded in the need to come to terms with a power on which they depend for their physical and economic wellbeing. So the Inuit relationship to the sea is inevitably affectively and, in turn, emotionally charged. This suggests that a religiously useful representation of the power manifest in the sea must evoke a world of feeling, rather than presenting that power in an affectively neutral way. So, for this reason too, we have good grounds for supposing that Sedna sums up the character of Inuit experience in relation to the sea in the manner of an aesthetic object.

We can draw upon Dufrenne's model to understand more exactly how this aesthetic representation works. Following Dufrenne, we may suppose that Sedna represents the power at work in the sea by evoking a set of feelings which recall the sea. Or more precisely, we may say that Sedna represents this power by projecting an appropriate affective world, that is, a world which both recalls the affective qualities of the sea, and shapes the Inuit perception of those qualities, by enveloping the sea within its atmosphere. Hence the stories of Sedna offer not some abstract system of reference, but a symbol (a concrete universal) in which the sea can be feelingly present.

Dufrenne's work provides a further reason for thinking of Sedna's capacity to represent the sea by reference to her ability to project an appropriate affective world. For Sedna is, evidently, a personification of the sea. ${ }^{16}$ And persons, Dufrenne suggests, provide a paradigm case of what it is to project an affective world. For instance, he speaks of a practical and affective Weltanschauung which each of us projects, and comments that:

This Weltanschauung is not a doctrine but rather...the way of being in the world which reveals itself in a personality. We are not surprised that it [this Weltanschauung] can turn itself into a world, the world of an aesthetic object, since each man already radiates a world. There is a nimbus of joy around the joyous man. We say of another that he exudes boredom. ${ }^{17}$ 
Similarly, Dufrenne writes that: 'Just as we identify an individual by a certain air which he has and which no particular sign can determine exactly, so the work has a certain quality which it radiates and by which it is animated through and through, even if we cannot delimit this quality with exactitude. ${ }^{18}$ Following these reflections, we might suggest that the Inuit are able to sum up the character of the sea through the figure of Sedna in rather the way that we are able to sum up the various actions of a human being through the idea of their personality. In each case, the unification is achieved by attributing to the phenomena a consistency of affective tone, or (in Dufrenne's terms) membership of a unitary affective world. In other words, in each case, the phenomena are united by summarizing, in a feeling-laden way, their affective significance for us.

It is worth noting that on this account, an artwork may bear a religious significance even if it lacks any explicitly religious content. For it is not only explicitly religious figures such as Sedna which are capable of evoking an affective world appropriate to the sea. An artwork without any explicit religious intent may also do so. For example, as we have seen, Dufrenne comments that Debussy's La Mer reveals the 'affective essence' of the sea. If that is so, then potentially a nonreligious work can carry the same sort of religious significance as Sedna, to the extent that like Sedna it can function as an affectively rich, eidetic representation of the sea.

Of course, this is not to say that Sedna and La Mer offer the same perspective on the 'affective essence' of the sea. On the contrary, we might suppose that the feelings evoked by the sea in different peoples, and different individuals, will vary according to its role in their lives, in socioeconomic and other terms. And no doubt, in these terms, the sea signifies something rather different for the Inuit and for a nineteenth- (and early twentieth-) century Frenchman. This suggests another condition which must be satisfied if an aesthetic complex is to carry religious significance in the style of Sedna. In general, we might suppose, an artwork's ability to bear a religious meaning in this way depends not only on its power to project an affective world corresponding to some region of human experience, but also on the existential depth of the feelings which are associated with that particular sphere. Sedna is religiously significant for the Inuit not only because she represents eidetically the felt significance of the sea, but also because a properly ordered relationship to the sea is essential for the flourishing of Inuit society. By contrast, most modern, Western people stand in a rather different, and existentially less serious, relationship to the sea. And accordingly, it is less likely that an artwork concerning the sea will be religiously significant for us, even if it should succeed in projecting an affective world which is for us reminiscent of the sea. Nevertheless, the example of La Mer suggests one way in which an artwork may, potentially, carry religious significance, insofar as it shares with Sedna the property of representing the sea, by virtue of evoking a set of feelings of the kind that recall the sea. 


\section{Applying Dufrenne's model: beyond the primal traditions}

I have been arguing that in the case of Sedna, religious representation has to do with the representational powers of an aesthetic complex, and specifically the ability of this complex to sum up the character of some region of human experience. And in turn I have argued that this ability can be fruitfully understood in the terms proposed by Dufrenne's theory, that is, by thinking of representation in terms of affective disclosure. We might wonder next whether this model can be extended beyond the Sedna kind of case, to encompass philosophically more sophisticated accounts of the divine nature.

I have suggested that Platonic and Thomistic conceptions of the sacred resemble Sedna insofar as they too postulate an affinity between the sacred and a swathe of human experience. More exactly, they can be seen as generalizations of the Sedna model insofar as they associate the divine with the totality of human experience, or with the world as a whole, rather than with a particular sphere of experience. Assuming the validity of this association, between the primal and these other approaches, there is no reason in principle why the model of aesthetic representation we have developed in relation to Sedna should not be applied in this further context. Here again, we would need to attribute to an artwork the capacity to represent the divine by evoking an affective complex which recalls a whole sphere of experience. More exactly, for the model to work in this case, we would have to assume that this affective complex may recall our experience in general (and not merely our experience of the sea or some other limited region of experience). Some may find this proposal controversial. However, in its defence, we may note the familiar view that the religions aim 'to establish powerful, pervasive, and long-lasting moods and motivations...' ${ }^{19}$ This perspective suggests that religious belief is associated with patterns of affective response which suffuse human experience in a fairly general way. I shall return to this thought shortly, in relation to an example drawn from Simone Weil.

There is a further significant point of difference between primal and Platonic traditions, in addition to the difference of scope which we have noted (insofar as primal religions are concerned simply with limited regions of experience, such as that relating to the sea). Primal religions, together with pantheism, think of religious powers as in principle (to a sufficiently acute observer) fully disclosed in the world. But of course, the great monotheistic traditions have tended to suppose that qualitatively, the divine in some way outstrips or transcends the world. We might ask next whether the model of representation we have been considering can be developed so as to accommodate this point of difference. Dufrenne offers an example which is relevant in this regard when he envisages the following situation:

Suppose that a captive in his prison, delivered to hatred and seeing the sky only 'beyond the rooftop', hears a Bach fugue.... He can not doubt that this world of 
Bach exists, even if it is reserved for enjoyment by others. There is joy, and it is of little importance which particular objects manifest it. ${ }^{20}$

Following this example, we might suppose that an image or piece of music, or some other aesthetic object, may evoke an affective complex which is richer than any evoked by the world of ordinary experience, which by contrast may seem to us a kind of prison. (Compare attempts to justify the arts by emphasizing the difference between the kinds of affective world which are available through artistic and ordinary empirical experience. For instance, Alan Goldman writes that in art: 'One escapes from natural and social worlds to which we are at best satisficingly adapted into worlds designed to challenge and satisfy, from which all extraneous noise has been extracted.' $)^{21}$

This provides a further way of understanding how our aesthetic model of representation can be extended to encompass Platonic accounts of the sacred (albeit that we are here giving art a more elevated role than any countenanced by Plato himself). To put the matter Platonically, we may think of an artwork as pointing towards the sacred, by evoking an affective world of pure joy, which the empirical world can echo, or in which it can participate, only in a limited, fragmentary kind of way. Hence just as Sedna represents a religious power by projecting an affective world which recalls the sea, so the Bach fugue, on this account, may represent the sacred by projecting an affective world which recalls a realm which surpasses the empirical world. In both cases, the representation works by projecting an affective world which is set in comparison with the affective world evoked by the empirical world. So in both cases, some perspective on the character of a swathe of human experience is presupposed. Moreover, in each case, the representation is in principle independent of any explicitly religious content, as the examples of $\mathrm{La} \mathrm{Mer}$ and the fugue indicate.

Moving further still from the Sedna kind of example, we might wonder whether this aesthetic account of our ability to represent the sacred can be extended to non- or antisacramental traditions, that is, traditions which see the divine not merely as surpassing, but as radically discontinuous qualitatively with the world of sense experience. The following passage from Simone Weil's spiritual autobiography offers one way of developing our model to include this sort of case (here again we revert to the sea). She writes:

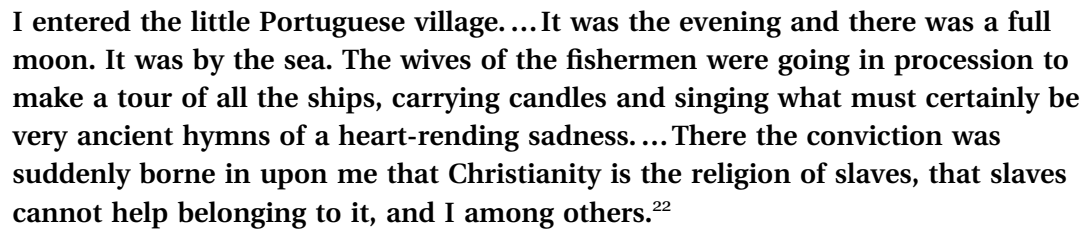

Here a hymn is said to evoke an affective world (a world of 'heart-rending sadness'). Implicitly, the passage also suggests that the empirical world evokes an affective world of this same kind, since Weil characterizes our ordinary existence 
as one of slavery. Thus far, this example seems like the Sedna kind of example: an artwork (a hymn) is said to evoke an affective world of the same kind as that evoked by the empirical world; and hence we may say that the hymn represents (in Dufrenne's special sense) the empirical world, just as Sedna represents the sea. But in the example Weil gives, the divine is not said to be akin to the empirical world: on the contrary, to think of our empirical existence as a state of slavery is to suggest that the empirical world is qualitatively distant from the divine. So in this case, we will not succeed in representing the sacred by representing the empirical world. Another model is needed.

In the case Weil describes, the artwork evokes an affective world (a world of slavery or heart-rending sadness) which coincides with the affective world evoked by the empirical world, but contrasts with the affective world which befits the divine. And accordingly, we may say, the artwork alludes to the sacred, by revealing God as qualitatively distant, or absent, from the empirical world. (I say 'alludes' rather than 'represents' since there is no attempt here to make God affectively present, by replicating the affective world we associate with the divine. It is rather the absence of God that is made affectively present.) Here too, religious reference does not seem to depend upon any explicit religious content. For (so far as we can tell) the hymns Weil describes derive their religious power not from any verbal recording of religious themes, or from any official religious context, but simply by virtue of projecting a religiously evocative affective world, and specifically, an affective world which reveals the divine by disclosing its distance or absence.

As well as throwing some light on the case of nonsacramental religions, Weil's remarks also offer another perspective on the question of whether human experience in general may have a certain affective character. Weil's comments suggest this is indeed a possibility. For the sense of enslavement, to which she alludes, is surely meant to characterize her experience in an utterly general way (and not simply when by the sea, or when listening to certain music). Of course, not all forms of Christianity will think of the world's affective significance in these terms; for example, we would expect a sacramental tradition to offer a more positive conception of the patterns of affective response which are fitting in relation to the world.

We can sum up our discussion schematically as follows. Suppose we call the complex of feelings or affective world evoked by an artwork WA; the affective world evoked by the empirical world (or some region thereof) WE; and the affective world which befits the divine (or religious powers otherwise characterized) WD. The primal traditions build on the assumption that the sacred is in principle fully disclosed in the empirical world, and accordingly on the assumption that WE and WD coincide. Hence an aesthetic complex such as Sedna will be able to represent the religious power manifest in the sea insofar as WA coincides with WE, and thereby coincides with WD. In other words, in this way, a figure like Sedna can represent the sea by evoking a set of feelings of the kind that recall the sea; and 
thereby she is able to represent the power at work in the sea, in the sense of making that power affectively present.

A Platonic conception of divinity starts from the assumption that the sacred outstrips the empirical world, and accordingly supposes that WD outstrips WE. Hence in the context of this tradition, an aesthetic complex can represent the divine insofar as WA outstrips WE, and thereby coincides with or points towards WD. On this approach too, an artwork represents the sacred by eliciting in us an affective response of the kind we associate with the divine. Finally, a nonsacramental approach supposes that the empirical world has no positive affinity with the divine, so that WD has no positive affinity with WE. Hence in this context, an aesthetic complex can allude to the divine insofar as WA coincides with WE, and thereby by negation or denial points towards WD. In each of these cases, reference to the divine is secured by offering a perspective on the felt significance of the empirical world (or some region thereof), WE, as compared with WA. WE is considered either to coincide with WA (in the case of primal and nonsacramental traditions) or to be surpassed by WA (in the case of Platonic traditions).

In general outline, these three approaches to representing the sacred appear to be exhaustive in terms of the history of religions, though they are not exhaustive logically. If we ask (i) do WA and WE tend to coincide?, and (ii) do WA and WD tend to coincide?, we may respond: (a) yes/yes; (b) yes/no; (c) no/yes; or (d) no/no. (a)-(c) here correspond respectively to the primal, nonsacramental and Platonic approaches. (a)-(c) also generate a response to (iii) do WE and WD tend to coincide? To be consistent, (a), (b) and (c) must reply respectively yes, no, no. For example, if WA coincides with WE but not with WD (the nonsacramental case), it follows that WE cannot coincide with WD.

\section{Some implications}

So far, I have been trying to establish the possibility of representations of the divine being mediated aesthetically, but I have not ventured to say whether such representations are at all common or important. Needless to say, there are other ways in which the divine can be represented, independently of any affective or aesthetic concern. For example, relatively abstract representations of the sacred will, presumably, be free of any allusion to the character of WE or WD (as when God is characterized simply as 'the source of being'). And accordingly artworks too, insofar as they offer simply a visual (or other) equivalent of a certain purely conceptual content, can also represent the divine without presupposing any understanding of WE or WD. However, it seems plausible to think that in practice, participation in a religious tradition will require the adoption of appropriate patterns of affective response, both in relation to the sacred realities postulated by that tradition and in relation to the world. This suggests that, for practical purposes, aesthetic considerations will have an important part to play in religious 
representation. I have been arguing, more exactly, that they may play this role insofar as representations of the sacred project an affective complex which stands in an appropriate relation to the affective complex associated with the empirical world (be it one of identity or one of surpassing).

For an example of how an affective, aesthetically grounded appreciation of a religious tradition's import may well prove more potent than a purely conceptual grasp of its meaning, we may return to the Simone Weil passage we have been discussing. It is clear that Weil understood the basic teachings of Christianity before the episode she relates; but on hearing the music of the Portuguese fisherfolk, she acquired a new sense of their significance, and it was only in the light of this new understanding that she came to see that she must consider herself as in some sense a Christian. Put in the terms of our discussion so far, and elaborating the example a little, we may say that through her encounter with Christian art, Weil came to a new understanding of the Christian conception of the affective character of the empirical world; and thereby she came to a new understanding of the Christian God.

These reflections invite some more general comment on the epistemology of religious belief. Notably, they suggest that, for practical purposes at least, religious understanding has an aesthetic dimension in at least two ways. First of all, the believer must gain access to the affective world which is presupposed in her tradition's talk of the gods or the sacred, where this world is projected by a particular artwork, or tradition of art, or some other aesthetically significant object of experience. And secondly, the believer must be able to identify with her tradition's sense of the affective significance of the empirical world.

In turn, therefore, nonbelief may have two specifically aesthetic sources. First of all, it may be that the nonbeliever has not gained access to the affective world which is presupposed in a faith's art and religious symbolism more generally. For example, I may never have grasped the precise quality of 'heart-rending sadness' to which Weil alludes. (It is worth noting that the affective quality in question will have a rather more particular character than can be captured in the phrase 'heartrending sadness' or, we might suppose, any other prosaic description.) We are all of us in this position in relation to at least some faith traditions, I suggest. To put the matter in William James's terms, certain faith traditions fail to present us with a 'live' hypothesis; in other words, they lie beyond our reach, not fundamentally because of reservations we have about their doctrinal teachings, or because we are ignorant of these teachings, but because the affective world they incarnate is not really alive for us psychologically speaking. ${ }^{23}$

Secondly, even if the nonbeliever understands the affective world which is inscribed in the believer's religious symbolism, WA, she may still be unable to share the believer's sense of the relationship of WA and WE. (For example, I may have grasped the quality of feeling Weil describes, but find that it does not coincide with my felt response to the empirical world: perhaps I cannot experience 
human life as a state of enslavement in the precise sense that Weil indicates.) Given the atmospheric dimension of aesthetic experience which we noted earlier, it seems that no quick judgement can be made about these matters. For if I immerse myself in the affective world of a particular faith tradition, by familiarizing myself with its images, stories and music, my own affective response to the world of everyday experience is likely to be shaped in some degree accordingly. Hence if I sense initially that Weil's WA is religiously irrelevant for me, because it fails to match my WE, this may merely indicate that I have yet to acquaint myself with WA with sufficient seriousness. In sum, aesthetic insight is presupposed in religious understanding both in respect of WA and in respect of the relation between WA and WE.

Of course, this is not to deny that there are also nonaesthetic sources of nonbelief. For someone might understand and find themselves in agreement with a tradition's WA and WE, and yet reject the tradition. For instance, I may be a philosophical materialist, and I may suppose that a given religious tradition is incompatible with my materialism. But such purely theoretical reservations about a religious tradition may well be somewhat rare, to the extent that religious belief in its life-setting is not generally philosophically self-conscious.

\section{Conclusions}

In this paper, I have tried to approach the general topic of religion and art using Mikel Dufrenne's proposal that an artwork projects an affective world, which may coincide with or surpass (and also help to shape) the affective world projected by the empirical world (or some region thereof). Accordingly, in the terms we have used, Dufrenne's work suggests the existence of a relationship between WA and WE. The philosophy of religion literature points in addition to a range of understandings of the relationship between WE and WD, depending upon whether WE coincides with WD, is outstripped by it, or differs from it (the approaches respectively of primal, Platonic and nonsacramental traditions). Putting together these two steps, relating in turn WA to WE, and WE to WD, we have distinguished three general ways in which the affective world of an artwork may be relevant for the purpose of representing the sacred, depending upon how WA is mapped onto WE, and WE onto WD. For example, if WA coincides with WE, and WE with WD, then WA will represent a religious power in the manner of a figure like Sedna (providing that WE is of sufficient existential seriousness).

In these ways, I have been exploring the general theme of religious representation as affective disclosure. And in turn, therefore, I have been arguing that aesthetic theory is important for understanding, from a theoretical point of view, the referential character of religious language. I have also proposed that representations of the gods may commonly function aesthetically, given the practical concerns of religious language (and more generally of religious imagery and other 
art forms). However, in this paper I have been more concerned to sketch the theoretical possibility of this sort of representation of the sacred, drawing on the Sedna case in particular, rather than to illustrate the aesthetic hypothesis in detail. (For example, I have left open the question of whether apparently credal language may be understood, at least in part, in these terms.)

If aesthetic questions are important for religious language in this way, then they will be important in corresponding degree for any account of the epistemology of religious belief. I have suggested that in practice, membership of a religious tradition presupposes an ability to understand the affective world projected by the tradition (WA), and an ability to take WA as a measure for one's own felt response to the empirical world (one's own WE). In both of these respects, religious understanding will be closely tied to aesthetic understanding.

In recent times philosophy of religion has benefited from exchanges with a variety of neighbouring philosophical disciplines, including philosophy of science and philosophy of perception. In this paper, I have tried to facilitate a conversation between the philosophy of religion and another neighbouring area of philosophical enquiry, namely aesthetics. The submission of this discussion is that an exchange of this kind is likely to be fruitful for both disciplines. In particular, by reflecting further on the aesthetic dimension of religious belief, philosophers of religion may hope to understand more clearly the role of affective commitments in religious understanding, and the religious power of art, including art which lacks any explicitly religious content. ${ }^{24}$

\section{Notes}

1. Mikel Dufrenne The Phenomenology of Aesthetic Experience, translated by Edward S. Casey et al. (Evanston DL: Northwestern University Press, 1973), first published in French, 1953.

2. 'Gods' in J. Wisdom Philosophy and Psychoanalysis (Oxford: Blackwell, 1953), 149-168.

3. Dufrenne Phenomenology, 378.

4. For an overview of the expressive approach, see John Andrew Fisher (ed.) Reflecting on Art (Mountain View CA: Mayfield Publishing Co., 1993), ch. 11.

5. Dufrenne Phenomenology, 137.

6. Ibid., 520.

7. Ibid., 179-180.

8. Ibid., 181.

9. Keith Ward Religion and Revelation: A Theology of Revelation in the World's Religions (Oxford: Clarendon Press, 1994), 65.

10. Ibid., 65. Ward's interpretation of Inuit religion is borne out by Daniel Merkur's detailed study of the same theme. See Merkur Powers Which We Do Not Know: The Gods and Spirits of the Inuit (Moscow DL: University of Idaho Press, 1991).

11. To name just one other example, see Godfrey Lienhardt's account of the religion of the Dinka: Divinity and Experience: The Religion of the Dinka (Oxford: Clarendon Press, 1961), 159-160.

12. See for example Aquinas Summa Theologiae, 1a. 3. 4, and, 1a. 47. 1.

13. Mircea Eliade 'Divinities: art and the divine', first published in English 1961, and reprinted in Diane Apostolos-Cappadona (ed.) Mircea Eliade: Symbolism, the Sacred and the Arts (New York NY: Crossroad, 1985), 56.

14. David Tracy 'The religious classic and the classic of art', in Diane Apostolos-Cappadona (ed.) Art, Creativity and the Sacred (New York NY: Crossroad, 1984), 248. 
15. Pope John Paul II Fides et Ratio (Sydney NSW: St Paul's Publications, 1998), section 12.

16. Compare Daniel Merkur's remark that Sedna is 'the personified idea of the sea and all its animals',

Powers Which We Do Not Know, 106.

17. Dufrenne Phenomenology, 177.

18. Ibid., 326-327.

19. The quotation is taken from Clifford Geertz, of course: 'Religion as a cultural system', in Geertz The Interpretation of Cultures: Selected Essays (New York NY: Basic Books, 1973), go.

20. Dufrenne Phenomenology, 519. The reference is from Verlaine.

21. Alan Goldman Aesthetic Value (Boulder CO: Westview Press, 1995), 155.

22. Simone Weil Waiting on God, Emma Craufurd (tr.) (London: Routledge \& Kegan Paul, 1979), 19-20. 23. See William James's essay 'The will to believe', in W. Rowe and W. Wainwright (eds) Philosophy of Religion: Selected Readings (San Diego CA: Harcourt Brace Jovanovich, 2nd edn, 1989), 406-410.

24. I am fortunate to have had the opportunity to present versions of this paper on a number of occasions, and have benefited greatly from the ensuing discussions. In this regard, I would like to thank in particular participants in the British Society for the Philosophy of Religion conference held in Oxford in September 1999, and my colleagues in the School of Philosophy and the School of Theology at the Australian Catholic University. I am also grateful to the Editor and Professor Patrick Sherry for their comments, which have helped me to clarify some of the paper's central themes. 